\title{
Docência e formação de professores (as): Cenários e perspectivas
}

\author{
Alba Regina Battisti de Souza (UDESC) \\ Lourival José Martins Filho (UDESC)
}

\begin{abstract}
Resumo
Este artigo é resultado de uma pesquisa sobre a formação docente considerando produções teóricas e políticas voltadas para a formação, mais especificamente o Programa Institucional de Bolsa de Iniciação à Docência (PIBID). As questões orientadoras são: quais os principais desafios e perspectivas para a docência segundo as produções teóricas em evidência? Como os bolsistas de ID (Iniciação à Docência) percebem as influências do PIBID na sua formação? Quais as relações entre as premissas teóricas e a efetiva contribuição do PIBID na formação dos licenciandos? Trata de um estudo bibliográfico conjugado com análise documental. A partir de uma abordagem qualitativa, os dados foram discutidos considerando princípios da análise de conteúdo. Dentre as tendências identificadas nas produções teóricas destacam-se: a concepção de docência como uma profissão altamente complexa na qual os professores lidam com interações humanas e situações diversas e adversas nas quais precisam mobilizar saberes, por exemplo, aqueles relacionados à própria experiência; o princípio do "protagonismo docente", no qual os professores são vistos como sujeitos, autores e mentores da construção de sua identidade profissional traçada ao longo do processo de formação inicial e no exercício da profissão; a relação universidade e instituições escolares numa perspectiva de integração de propostas e projetos de formação. Em vários aspectos há certa consonância entre as produções sobre a formação docente e as vivências dos Bolsistas de ID sobre o Programa, como foi possível identificar nos relatos: propicia uma maior articulação entre teoria e prática; promove um reconhecimento mais aprofundado do contexto escolar e, em especial, da sala de aula; viabiliza a construção de saberes específicos para a prática docente, com crescente autonomia e protagonismo.
\end{abstract}

Palavras-chave: formação docente, saberes docentes, educação básica, PIBID

\section{Resumen}

El artículo es el resultado de la investigación sobre la formación del profesorado teniendo en cuenta las producciones teóricas y políticas centrado en la formación, en concreto PIBID - Programa Institucional de Iniciación de subvención para la enseñanza. Las preguntas orientadoras son: ¿cuáles son los principales retos y perspectivas de la enseñanza de acuerdo a las producciones teóricas en evidencia? Como estudiosos ID (Iniciación a la Docencia) se dan cuenta de las influencias de PIBID en su formación? ¿Cuáles son las relaciones entre los supuestos teóricos y la contribución efectiva de PIBID en la formación de los futuros docentes? Es una conjunción estudio bibliográfico con el análisis de documentos. Desde un enfoque cualitativo, se discutieron los datos teniendo en cuenta los principios de análisis de contenido. Entre las tendencias identificadas en las producciones teóricas son: el diseño de la enseñanza como una profesión muy compleja en la que los maestros se ocupan de las interacciones humanas y situaciones diferentes y adversos que deben movilizar los conocimientos, incluidos los relacionados con la experiencia personal; el principio de "rol docente" en la que los profesores son vistos como temas, autores y mentores de la construcción de su identidad profesional forjado durante el proceso de formación inicial y en la profesión; relaciones universitarias e instituciones educativas desde la perspectiva de las propuestas de integración y proyectos de formación. En muchos sentidos, hay una cierta consonancia entre las

$$
=40=
$$


producciones en la formación del profesorado y las experiencias de I + D becarios en el programa, como se ha identificado en los informes: proporciona una mayor articulación teoría y la práctica; promueve un mayor reconocimiento del contexto escolar y en particular de la clase; permite la construcción de conocimientos específicos para la enseñanza, con el aumento de la autonomía y el liderazgo.

Palabras claves: formación del profesorado; maestros del conocimiento; educación primaria.

\begin{abstract}
This article is the result of a research on teacher training considering theoretical and political productions on the education training, specifically the Institutional Program of the Initiation to Teaching Grant (PIBID - Programa Institucional de Bolsa de Iniciação à Docência). The guiding questions are: what are the main challenges and perspectives for teaching according to the theoretical productions in evidence? How do the PIBID scholarship students perceive the influences of the Program in their formation? What are the relationships between the theoretical premises and the effective contribution of PIBID in the training of this students? It is a bibliographical study combined with documentary analysis. From a qualitative approach, the data were discussed considering principles of a content analysis. Among the trends identified in theoretical productions are: the conception of teaching as a highly complex profession in which teachers deal with human interactions and diverse and adverse situations in which they need to mobilize knowledge, for example, those related to their own experience; the principle of "teacher as protagonist", in which teachers are seen as subjects, authors and mentors of the construction of their professional identity drawn during the initial training process in the exercise of the profession; the relationship between universities and schools with a view towards integrating proposals and training projects. In several respects, there is a certain consonance between the productions about the teacher formation and the experiences of the students on the Program, as it was possible to identify in the reports that it allows a greater articulation between theory and practice; promotes a more in-depth recognition of the school context and, in particular, of the classroom; enables the construction of specific knowledge for the teaching practice, with increasing autonomy and protagonism.
\end{abstract}

Keywords: teacher training; teacher knowledge, basic education; PIBID.

\title{
Pontos de partida
}

Há algum tempo as reiteradas críticas ao distanciamento entre o que é propagado nos cursos de formação docente e os efeitos no cotidiano educacional, incluindo as atividades de ensino, pesquisa e extensão, têm provocado os estudiosos do campo da educação. Além disso, é possível encontrar em propostas e documentos oficiais da esfera educacional diversas considerações sobre aspectos que, conforme destacam, precisariam ser revistos e até superados.

Este estudo resulta de uma pesquisa do tipo bibliográfica e documental e apresenta a análise de produções acadêmicas e algumas propostas oficiais que abordam a formação de professores com o objetivo de compreender quais as principais tendências sobre a 
docência na atualidade e suas possíveis repercussões na formação e na atuação do docente da Educação Básica. Para sistematização e discussão dos dados foram utilizados alguns princípios da análise de conteúdo segundo Franco (2003) e Bardin (2009) .

Ao selecionar e sistematizar os dados sobre as discussões mais recorrentes nas produções pesquisadas, destacam-se neste artigo três perspectivas a serem tratadas: 1) a concepção de docência como uma profissão altamente complexa na qual os professores lidam com interações humanas e situações diversas e adversas e nas quais precisam mobilizar saberes, dentre eles aqueles relacionados à própria experiência; 2) a ideia de "protagonismo docente", ou seja, os professores sendo vistos como sujeitos, autores e mentores de sua construção de identidade profissional traçada ao longo do processo de formação inicial e no exercício da profissão; 3) a relação universidade e instituições escolares em uma perspectiva de integração de propostas e projetos de formação.

Quanto aos impactos do Programa Institucional de Bolsa de Iniciação à Docência (PIBID) identificados a partir dos relatos dos bolsistas, contidos em documentos de avaliação do programa, observa-se uma significativa aproximação com as produções sobre formação docente mais veiculadas na atualidade, principalmente quanto à relação teoria e prática, ao reconhecimento do contexto escolar paralelo à formação e à possibilidade do desenvolvimento de saberes específicos da prática docente.

Ao revisitar alguns estudos sobre a docência ao longo de nossa história, é relevante destacar as afirmações de Tardif e Lessard (2008). Segundo os autores, por muito tempo o ensino foi reconhecido como uma vocação, um apostolado ou sacerdócio leigo; seu exercício tinha como base as qualidades morais que o bom mestre deveria ter. Nas últimas décadas, com o processo de massificação do ensino, houve um movimento em prol do reconhecimento da docência como ofício; e, mais recentemente há uma tendência em se considerar - ensino na perspectiva da profissionalidade docente. As três concepções - vocação, ofício e profissão - exprimem uma linha de evolução do ensino, que, em maior ou menor grau, estão presentes na contemporaneidade.

Para Nóvoa (2009:13), na atualidade os professores retornaram ao centro das atenções, reaparecendo no século XXI, depois de quase quarenta anos de relativa invisibilidade "como elementos insubstituíveis não só na promoção das aprendizagens, mas também na construção de processos de inclusão que respondam aos desafios da

$$
=42=
$$


diversidade e no desenvolvimento de métodos apropriados de utilização das novas tecnologias".

\section{Docência: entre tensões e dilemas}

A docência é um trabalho como qualquer outro trabalho humano (Tardif \& Lessard, 2007), se considerarmos que trabalhar é agir em função de um objetivo e em um determinado contexto - ensinar é agir na sala de aula com o objetivo de promover a aprendizagem e a socialização dos alunos. Porém, por se tratar de uma profissão de interações humanas, na qual o docente é parte integrante, sua personalidade torna-se uma tecnologia do trabalho, na qual muitos desafios e dilemas estarão sempre presentes.

o nível de complexidade que envolve a docência é elevado, o professor está constantemente diante de urgências e incertezas. Perrenoud (2001) entende que a urgência se refere à necessidade de compreender a dinamicidade de um sistema complexo, no qual o docente deve agir, tomar decisões e fazer encaminhamentos cujos resultados são marcados pelas incertezas.

Nesse sentido, a docência está em contínua transformação, não havendo grandes regularidades na ação docente; mesmo compreendendo as rotinas do ambiente escolar e acadêmico, é impossível repetir processos na mesma intensidade e com os mesmos significados. Os docentes aprendem com o que fazem e usam esses saberes para propor novas experiências podendo até guardar elementos das anteriores, mas sempre ressignificadas no novo contexto (Cunha, 2004). Trata-se de um trabalho "...cujo objeto não é constituído de matéria inerte ou de símbolos, mas de relações humanas com pessoas capazes de iniciativa e dotadas de uma certa capacidade de resistir ou de participar da ação dos professores." (Tardif \& Lessard, 2007: 35) .

Em meio a todas as exigências sociais, de caráter amplo, há um conjunto de condicionantes específicos dos ambientes nos quais os docentes atuam, caracterizados por aspectos estruturais, administrativos e pedagógicos, somados às variáveis do espaço onde ocorre efetivamente a docência, acrescendo-se as características socioculturais e as expectativas do grupo de estudantes. Assim, ser docente é lidar com um conjunto de variáveis presentes no cotidiano, desde o planejamento, elaborado na expectativa da participação de um determinado grupo de pessoas, cuja reação pode ser totalmente diferente da esperada aos aspectos que envolvem a $=43=$

ISSN: 2447-1267 Santa Catarina, v.5, n.1, ano 3, março de 2017. 
instituição escolar, como as relações profissionais e com a comunidade escolar, os materiais e recursos disponíveis ou não, a organização curricular, as demandas específicas da turma e da escola, dentre tantos outros itens. Dessa forma, a docência não é uma tarefa simples, meramente repetitiva, mas sim algo que exige criatividade, constante atenção, redirecionamentos e formação contínua.

Outro aspecto que confere à docência uma atividade repleta de dilemas, pluralidade e pouca regularidade, é o fato de esta ser uma atividade essencialmente humana, ou seja, que se sustenta por meio de relações e interações com e entre seres humanos. São inúmeras as pessoas com as quais o professor tem de lidar, em um mesmo espaço e em geral por um período de tempo considerável. Nesse conjunto de relações, ele administra tensões, resistências, atitudes diversas e, em alguns casos, até reações adversas.

\section{Autores e protagonistas?}

Partindo do princípio de que as pessoas são fundamentais na organização da escola (Alarcão, 2001) e que elas deveriam protagonizar suas ações, sendo os professores - por sua permanência mais duradoura em relação aos alunos - os atores principais e sociais e que têm um papel a desempenhar na política educativa; além disso, no seio da escola, as suas atividades desenrolam-se no cruzamento das interações político-administrativo-curricularpedagógicas.

No percurso da investigação foram encontradas várias produções sobre as pesquisas autobiográficas, a princípio como uma referência metodológica para estudos sobre as práticas de formação, porém, ao verificar as discussões presentes nestas propostas, percebe-se como os professores tomam uma posição de destaque. Como exemplo, tem-se os estudos de Souza (2014), que afirma que o trabalho com histórias vem apresentando uma gradativa consolidação no campo educacional brasileiro e para sujeitos em processo de formação, pois, ao narrarem suas experiências através de suas narrativas orais e/ou escritas, expõem diferentes marcas que possibilitam construções de identidades pessoais e coletivas. Ainda segundo o autor:

Pesquisas com histórias de vida no campo educacional evidenciam a pessoa do professor, ao ressaltar a relevância da subjetividade como um dos conceitos articuladores dos questionamentos teóricos vigentes e das propostas que $=44=$

ISSN: 2447-1267 Santa Catarina, v.5, n.1, ano 3, março de 2017. 
realizam o estudo do método. Novos conceitos para a compreensão do trabalho docente surgiram com os estudos educacionais, cujas abordagens de pesquisa passaram a reconhecer o professor como sujeito, trazendo à tona a necessidade de investigar os saberes de referência dos professores sobre suas ações e pensamentos caracterizando-os inclusive, como sujeitos de um saber e de um fazer inerentes à profissão. (Souza, 2008:144).

As histórias de vida também têm sido reconhecidas como uma dupla função (Souza, 2014), pois, além de sua utilização como método de investigação das ciências da educação também têm sido aplicadas no processo de formação de novos professores por meio de memoriais acadêmicos. Tanto em uma como na outra forma de aplicação - professor ganha destaque, uma vez que tem em suas memórias uma significativa referência para refletir, analisar ou redimensionar sua trajetória em uma condição mais ativa.

A utilização das "histórias de vida" como método é definida segundo diversas compreensões, porém, como explica Alcoforado (2014), comumente baseiam-se no princípio de que é sempre a própria pessoa que, ao elaborar uma compreensão total ou parcial do seu percurso de vida "...forma-se e, ao ganhar consciência do processo e das condições de construção de seu conhecimento, desenvolve uma completa implicação pessoal nesse mesmo processo, podendo imprimir uma continuidade temporal no presente e fazendo a sua projeção no futuro." (2014: 78).

Segundo Nóvoa (2009), é preciso uma dinâmica na qual o professor se integre ativamente:

[...] nossas propostas teóricas só fazem sentido se forem construídas dentro da profissão, se forem apropriadas a partir de uma reflexão dos professores sobre o seu próprio trabalho. Enquanto forem apenas injunções do exterior, serão bem pobres as mudanças que terão lugar no interior do campo profissional docente (2009: 19).

\section{Entre a necessidade e a urgência}

Em geral o posterior campo de trabalho dos docentes em formação fica um tanto quanto distante, mesmo nos estágios a convivência com o contexto escolar ainda é muito pontual, na maioria dos casos, restringindo-se mais ao "conhecer" do que ao "conviver". Não obstante a necessidade de conhecer as instituições, uma aproximação real entre universidade e escolas deveria constituir um projeto comum, ultrapassando a antiga fórmula: a $=45=$

ISSN: 2447-1267 Santa Catarina, v.5, n.1, ano 3, março de 2017. 
universidade "forma" e a escola "recebe" os novos docentes. Assim, a responsabilidade sobre a formação inicial e continuada poderia ser de ambas, resguardando suas peculiaridades, mas com um envolvimento comum. Nas instituições formadoras em geral apenas os professores responsáveis pelo estágio têm contato com as instituições escolares e esta é uma questão merecedora de atenção, tal como alerta Nóvoa (2009):

Muitas vezes, e isto é um problema de fundo as instituições de
formação de professores, ignoram ou conhecem mal a realidade
das escolas, especialmente do ensino fundamental. É
fundamental assegurar que a riqueza e a complexidade do
ensino se tornem visíveis, do ponto de vista profissional e
científico, adquirindo um estatuto idêntico a outros campos
de trabalho acadêmico e criativo. E, ao mesmo tempo, é
essencial reforçar dispositivos e práticas de formação de
professores baseadas numa investigação que tenha como
problemática a ação docente e o trabalho escolar. (2009: 22).

No Brasil, podem-se apontar algumas proposições para formação docente como a necessidade de se construir projetos e ações de formação inicial e continuada de forma articulada entre instituições formadoras, instituições educacionais da Educação Básica e sistemas de ensino, porém faz-se necessário um conjunto de políticas públicas que incentive e valorize com mais ênfase algumas iniciativas e deem espaço para outras. A esse respeito o PIBID oferecido pela Coordenação de Aperfeiçoamento de Pessoal de Nível Superior (CAPES) do Ministério da Educação (MEC), como várias pesquisas têm indicado, demonstra um nível de efetividade merecedor de mais atenção e talvez represente uma alternativa para dirimir em parte várias críticas sobre o processo de formação docente, dentre as quais se encontra a desarticulação teoria e prática e a excessiva burocratização dos estágios supervisionados em docência.

Ao que indica a Portaria $n^{\circ}$ 096, de 18 de julho de 2013 que regulamenta o Programa Institucional de Bolsa de Iniciação à Docência (PIBID), a Seção II, Art. $4^{\circ}$, apresenta objetivos que primam pela aproximação entre universidade e escola, tal como se pode perceber no inciso III: "elevar a qualidade da formação inicial de professores nos cursos de licenciatura, promovendo a integração entre educação superior e educação básica". (CAPES, 2013: 2). Tal integração, em especial no que diz respeito à inserção de docentes em formação é detalhada no inciso IV do mesmo artigo:

Inserir os licenciandos no cotidiano de escolas da rede pública de educação, proporcionando-lhes portunidades de criação e participação em experiências metodológicas, 
tecnológicas e práticas docentes de caráter inovador e interdisciplinar que busquem a superação de problemas identificados no processo de ensino aprendizagem. (CAPES, 2013: 2).

Foi sancionada a Lei n $13.005 / 2014$ referente ao novo Plano Nacional de Educação (PNE) para o decênio 2014-2024. Dentre as vinte metas, destacam-se algumas ações da Meta 15, que trata da formação dos profissionais da educação, ressaltando a relação com as demandas da Educação Básica, (Brandão, 2014:.75-76), no item 3: Ampliar programa permanente de iniciação à docência a estudantes matriculados em cursos de licenciatura, a fim de aprimorar a formação de profissionais para atuar no magistério da educação básica." E no item 8: "Valorizar as práticas de ensino e os estágios nos cursos de formação de nível médio e superior dos profissionais da educação, visando ao trabalho sistemático de articulação entre a formação acadêmica e as demandas da educação básica."

Cabem aqui, no entanto, algumas indagações: se nos reportarmos às propostas curriculares dos cursos de Licenciatura, ou mesmo para as práticas realizadas, encontraremos de forma objetiva e concreta a articulação com as demandas da Educação Básica? Os estágios, seus projetos se configuram em proposições elaboradas em conjunto com as instituições educacionais? As políticas públicas em educação têm primado mesmo para uma real articulação entre escolas e universidades? Por fim, o que os professores que atuam na formação e gestão dos cursos de licenciatura entendem por "demandas" da Educação Básica?

A partir desse conjunto de indagações, pode-se deduzir que buscar alternativas para uma maior integração entre as demandas da educação básica é urgente, e esta é uma responsabilidade de diversos segmentos, como agências formadoras, sistemas de ensino e gestores. Tomar como análise iniciativas que têm mobilizado diversos setores em prol da formação, como o PIBID, pode ser uma possibilidade de se repensar alguns aspectos da formação, em especial, como passamos a tratar neste estudo, quando buscamos entender como o bolsista, que será o futuro professor se reconhece nesse processo. 


\title{
O PIBID em foco
}

Nesta seção, a partir da análise de um questionário que faz parte da documentação do PIBID de um Curso de Pedagogia (Anos Iniciais), são consideradas as vivências relatadas por dez bolsistas de Iniciação à Docência. Os trechos dos questionários são identificados pela letra $R$ (Respondente) seguido por um numeral. Destaca-se que estes questionários se configuram em documentos, pois fizeram parte do processo de avaliação do Programa, aplicados pelos coordenadores de área.

A pergunta considerada uma das perguntas-chave do questionário - Quais as principais aprendizagens que o programa tem lhe proporcionado? - de fato indaga, afinal, o que os bolsistas afirmam ter aprendido com relação ao exercício da docência?

\begin{abstract}
"Através do programa estou tendo a oportunidade de entender a importância e a necessidade que o professor tem de planejar suas aulas, bem como de adapta-lo já que nem sempre as coisas saem como foi esperado, por isso o professor tem que ser dinâmico e flexível em suas ações. Além disso, o PIBID tem me feito pensar em uma educação que faça os alunos refletirem, se tornarem seres críticos, daí se dá a importância de nunca dar respostar prontas aos educandos, e sim fazê-los buscar suas próprias conclusões." (R2)
\end{abstract}

Essa convivência com a dinâmica da escola, da sala de aula e do trabalho docente no cotidiano da escola, aproxima o bolsista PIBID de um contexto no qual irá atuar, possibilitando a compreensão de princípios e conceitos com os quais tem acesso em um âmbito teórico na graduação, como planejamento, e acompanhamento do processo de aprendizagem. Nessa direção a próxima respondente corrobora:

\begin{abstract}
"Com a minha participação no PIBID eu consigo compreender melhor o funcionamento de uma unidade escolar, do trabalho desenvolvido com turmas de anos iniciais, bem como conciliar os conhecimentos teóricos vistos na faculdade com as práticas pedagógicas dos profissionais atuantes, além de propor atividades diversificadas com o objetivo de contribuir na aprendizagem dos alunos. Também é possível refletir sobre que tipo de profissional eu quero ser e sobre os desafios da profissão docente na atualidade." (R5)
\end{abstract}

o contato mais direto e contínuo com o professor que atua na sala de aula merece atenção. Em geral a pessoa referência nos processos de formação em campo, como nos estágios, é um docente de graduação, responsável por coordenar e orientar todas as etapas. $=48=$ 
O PIBID, ao incluir os professores da escola no programa, como coformadores, os imbui de outra responsabilidade, para além de "receber" os licenciandos, pois criam uma relação com os bolsistas que os valoriza muito mais. Quanto às aprendizagens, destacam a compreensão do funcionamento da escola, do trabalho nos anos iniciais, do planejamento das aulas e da atitude do professor diante das novidades que possam ocorrer:

"O PIBID também traz aprendizagens nos momentos que estamos em sala de aula e visualizamos como a professora regente da turma explica tal conteúdo aos alunos, qual a metodologia utilizada etc. Também experimentamos situações de aprendizado quando ajudamos as crianças na realização de atividades e, ainda, quando levamos para elas atividades preparadas por nós, bolsistas. Nesses momentos sentimos o quanto é significativo esse momento de aprendizagem para os alunos, o quanto eles têm "fome" de perguntas, dúvidas, afirmações; desse jeito percebemos que além de ensinar, também aprendemos." (R4)

Reconhecer a docência como uma atividade pautada também na reflexão, na discussão e trabalho coletivo também é um importante exercício, ao que demonstra outro bolsista:

\begin{abstract}
"Acredito que, primeiramente, nos é proporcionado o conhecimento do 'caminhar' da escola e dos seus profissionais. Participamos, por exemplo, de reuniões pedagógicas que abordam assuntos de ordem burocrática, como a decisão do calendário escolar, datas de festas temáticas e entregas de boletim etc. Por outro lado, também nessas reuniões e em outros momentos, temos a possibilidade de participar de formações pedagógicas que trazem novos conhecimentos e nos enriquecem com experiências." (R7)
\end{abstract}

Os cursos de licenciatura em geral se limitam à formação docente por meio de estágios curtos e pontuais e se eximem da responsabilidade com o egresso, ou, no máximo, aplicam pesquisas sobre o papel da graduação na sua formação. Ir além da constatação das dificuldades dos ingressantes, significa também pensar e propor uma formação mais próxima do contexto de atuação propiciando um real convívio dos licenciandos com o cotidiano da cultura escolar o mais cedo possível. Nóvoa (2009) traz algo interessante sobre a realidade dos docentes "iniciantes":

Um momento particularmente sensível na formação de professores é a fase de indução profissional, isto é, os primeiros anos de exercício docente. Grande parte da nossa vida profissional joga-se nestes anos iniciais e na forma como nos integramos na escola e no professorado. Neste sentido, este momento deve ser organizado como parte integrante do programa de formação em articulação com a licenciatura e o mestrado. (Nóvoa, 2009: 38). 
Outra questão foi sobre como os bolsistas percebem a relação entre as políticas públicas para a educação básica e as reais condições de trabalho dos professores, ao que um bolsista descreveu que :

\begin{abstract}
"O contato com a escola e, mais especificamente, com a educação pública me faz refletir constantemente acerca de muitos aspectos estudados ao longo do curso de Pedagogia. Consigo perceber a importância da formação continuada para o aprimoramento do trabalho dos educadores; a importância lou a falta!) de políticas públicas direcionadas para a educação e para proporcionar melhor condições de trabalho aos professores e melhores condições de aprendizagem aos alunos; a necessidade de um contato mais profundo com as instituições escolares, no caso de estudantes de Pedagogia em formação." (R5)
\end{abstract}

Os depoimentos indicam que a inserção na escola durante a graduação possibilita o contato com a profissão e assim conhecer a grande diversidade de questões, problemas e possibilidades do trabalho docente. Para Tardif \& Lessard (2008):

[...] os saberes que servem de base para o ensino, tais como são vistos pelos professores, não se limitam a conteúdos bem circunscritos que dependem de um conhecimento especializado. Eles abrangem uma grande diversidade de objetos, de questões, de problemas que estão todos relacionados com seu trabalho. Além disso, não correspondem, ou pelo menos muito pouco, aos conhecimentos teóricos obtidos na universidade e produzidos pela pesquisa na área de Educação: para os professores de profissão, a experiência do trabalho parece ser fonte privilegiada de seu saber-ensinar. (Tardif \& Lessard, 2008: 61).

Sobre os principais desafios e perspectivas, os bolsistas questionam os rumos da educação, e demonstram um compromisso de repensar a prática pedagógica:

"Assumir a escola como um espaço político, de exercer a cidadania; olhar para os estudantes e entendê-los dentro de todo um contexto que envolve sua história, a família e suas condições econômicas e sociais; estar atento aos conflitos internos presentes no dia a dia da escola, a precarização da profissão, o compromisso de repensar a prática pedagógica para melhoria e qualidade de ensino." (R6)

Outra preocupação é com relação à política de educação inclusiva. Torna-se evidente a distância entre o discurso de inclusão e a sua prática real:

"Penso que o principal desafio está ligado à educação especial. Muitos têm a visão de que a educação especial nas escolas (tanto públicas como privadas), de que ela é só $=50=$ 
inclusiva. Na minha visão a educação especial não está conectada a somente isso. É um espaço de aprendizagem dos conteúdos sim, para essas crianças com necessidades especiais. É um descaso com essas crianças, observei muitas vezes essas crianças serem deixadas de lado, pois não há atividades voltadas para suas necessidades. Penso que esse aspecto é um dos principais desafios das escolas públicas." $(\mathrm{R} 8)$

O período inicial na docência é difícil e crítico, em muitos casos, devido à estrutura e organização da instituição agravado pela falta de experiência e à ausência de um acompanhamento sistematizado:

"Ao mesmo tempo em que tenho vontade de estar dentro das instituições para poder mudar algumas práticas exercidas, tenho anseio de, após alguns anos, estar decepcionada com a realidade da educação e perceber que é uma luta 'vencida'." (R9)

Mesmo cientes das condições dos professores da Educação Básica na atualidade, grande parte dos bolsistas pretende permanecer na área da educação e existe uma preocupação sobre "como" atuar na docência diante de tantos desafios:

\begin{abstract}
"Sim. Tenho uma grande vontade em continuar trabalhando em sala de aula. Apesar de que algumas vezes desanima alguns atos e contradições no âmbito educacional; o ato de ser docente, de ensinar e ter contato com a escola e com os alunos me encoraja e me incentiva para a realização de importantes trabalhos. Penso que o mínimo que eu faça, mas com carinho, dedicação e comprometimento irá resultar de forma positiva no processo de ensino e aprendizagem dos alunos." (R7)
\end{abstract}

A compreensão da docência integrada a um contexto escolar e a necessidade do trabalho coletivo, da cooperação, faz-se presente na interpretação de um bolsista PIBID que também pretende continuar na carreira:

\footnotetext{
"Sim, ainda não decidi qual área, gosto de séries iniciais e orientação educacional, mas o PIBID está sendo decisivo na minha escolha, pois estou ciente da realidade escolar, e o fundamental é saber que posso fazer a diferença se optar por qualquer uma dessas opções, o PIBID tem me mostrado que o professor não é responsável e nem consegue fazer tudo sozinho, e que para fazer a diferença precisa que o coletivo coopere, trabalhe em conjunto, e o principal conjunto são os envolvidos na escola e a família." (R10)
} 
Os depoimentos revelam também muito compromisso e reconhecimento do papel docente na vida de uma criança, pois buscam uma "...humana docência, onde ser educador é ser o mestre de obras do projeto arquitetado para sermos humanos" (Arroyo, 2000: 41); e através de um outro depoimento, podemos constatar: "Pretendo fazer com que os alunos se sintam bem na escola, e não tenham mais o - olha que escola é 'ruim', 'chata' -, e sim que vejam a importância dessa instituição e assim sejam agentes das suas vidas." (R8) .

Tardif (2002) defende duas teses: na primeira, afirma que os professores são sujeitos dos conhecimentos e possuem saberes específicos ao seu ofício; e, na segunda, que a prática, ou seja, o seu cotidiano, não é somente um lugar de aplicação de saberes, produzidos por outros, mas também um espaço de produção, de transformação e de mobilização de saberes que lhes são próprios. Assim, a inserção contínua, sistemática e intencional dos licenciandos no contexto escolar pode possibilitar, além da convivência e da compreensão da instituição, a elaboração e a prática de saberes específicos da docência.

\section{Ainda compartilhando}

As análises do estudo demonstram um significativo avanço no âmbito das pesquisas sobre a docência possibilitando identificar algumas tendências aqui tratadas, tais como: compreensão da docência em sua complexidade e dinamicidade, a ideia do protagonismo docente e a necessidade de uma articulação mais efetiva entre escola e universidade (agências formadoras). A importância da profissionalidade docente permeia os estudos, em uma tentativa constante de ressaltar que esse processo exige conhecimentos específicos e legitimados academicamente e na ação, como decorrência dos saberes da experiência.

Destacam-se também os estudos sobre a escola como um importante espaço de formação docente inicial e continuada; uma maior articulação entre ensino e pesquisa; uma maior atenção das políticas públicas de formação docente e a formação continuada de professores em/de rede.

$\mathrm{Na}$ busca da superação do tão denunciado afastamento entre teoria e prática, ressaltam-se a necessidade de políticas de formação partilhadas, parcerias efetivas e contínuas, mudança de perspectiva das ações de cunho pessoal para institucional.

$$
=52=
$$

ISSN: 2447-1267 Santa Catarina, v.5, n.1, ano 3, março de 2017. 
Os autores que postulam as novas tendências de formação docente, em geral advogam que as avaliações dos grandes projetos têm demonstrado poucas alterações as coordenadas básicas do sistema educativo, concretizadas nas escolas, quando não há o envolvimento efetivo dos docentes, pois se espera que transformem as práticas a partir das diretrizes elaboradas por um grupo pensante.

No entanto também é importante salientar a dimensão que os discursos sobre a formação docente foram tomando ao longo dos últimos anos e, ao mesmo tempo, se dissipando em função das poucas mudanças provocadas, assim ainda tem-se um grande desafio pela frente como responsabilidade pedagógica, social e política em prol de uma Educação Básica de qualidade e, sem dúvidas, como os estudos têm demonstrado, os professores devem fazer parte deste processo de forma atuante e central, implicando assim em um necessário reconhecimento e valorização do seu trabalho.

Nesse caminhar, os autores que postulam as novas tendências de formação docente, em geral, advogam que as avaliações dos grandes projetos têm demonstrado que estes alteram pouco as coordenadas básicas do sistema educativo, concretizadas nas escolas, quando não há o envolvimento efetivo dos docentes, pois se espera que as práticas sejam transformadas a partir das diretrizes elaboradas por um grupo pensante.

Nessa perspectiva, as respostas dos bolsistas PIBID são ricas em "pistas" para que se repense a formação inicial docente. Eles consideram a articulação teoria e prática como fundamental, mas ponderam que esse processo não é fácil, sentem dificuldade em efetivar aquilo que definem como "fazer diferente" e convivem com um certo distanciamento da universidade frente ao cotidiano da escola.

Os bolsistas PIBID representam o discurso de um grupo de jovens entusiastas por uma educação de maior qualidade e se colocam à disposição desse movimento, mas também já sinalizam o receio de mais adiante serem "vencidos" e se inserirem em uma espécie de rotina pessimista e comodista. São depoimentos repletos de questionamentos, expectativas e esperança, mas também de angústias e incertezas. Nada muito diferente do que se tem ouvido, visto e lido, porém, quando são oriundos de pessoas prestes a adentrar na vida profissional, trazem alguns alertas, merecedores de maior atenção por parte de várias instâncias, como gestores da educação, agências formadoras, e de todos/as que têm alguma participação ou atuação nas políticas públicas de formação.

$$
=53=
$$


Diante das análises realizadas constatou-se que o PIBID tem tido um efeito bastante positivo e pode, em conjunto com outros programas e ações, compor uma importante iniciativa na construção de novas possibilidades de formação docente vinculada às demandas da Educação Básica, na integração escola e universidade, na valorização da carreira de professor e na conquista da profissionalidade docente. Quiçá o programa seja forte o suficiente para, em conjunto com outras alternativas e medidas políticas, manter e expandir o encantamento expresso pela bolsista (R7) : "O contato com a sala de aula, com a escola, enfim com o processo ensino aprendizagem dos alunos é o que mais me encanta. O Programa proporciona você se sentir seguro ante a experiência de ser professor." 


\section{Referências}

Alarcão, I. (2001). A escola reflexiva. In I. Alarcão (Ed.), Escola reflexiva e nova racionalidade (pp. 15-30). Porto Alegre: Artmed Editora.

Alcoforado, L. (2014, jan.-abr.). Desenvolvimento profissional, profissionalidade e formação continuada de professores: possíveis contributos dos relatos autobiográficos profissionais. Revista Educação, 39 (1), pp. 65-84.

Arroyo, M. (2000). Ofício de mestre: Imagens e auto-imagens. Petrópolis: Vozes.

Bardin, L. (2009). Análise de conteúdo. Lisboa: Edições 70 LDA.

Brandão, C. F. (2014). Os desafios do novo Plano Nacional (PNE - Lei n. 13.005/14): comentários sobre suas metas e estratégias. São Paulo: Avercamp.

Coordenação de Aperfeiçoamento de Pessoal de Nível Superior (CAPES) . (2010) . Portaria n. 260, de 30 de dezembro de 2010. Normas Gerais do Programa Institucional de Bolsa de Iniciação à Docência - PIBID. Disponível em: https://www.capes.gov.br/images/stories/download/legislacao/Portaria260_PIBI D2011_NomasGerais.pdf

Coordenação de Aperfeiçoamento de Pessoal de Nível Superior (CAPES). (2011). Programa Institucional de Bolsa de Iniciação à Docência. Edital n.

001/2011/CAPES. Disponível em:

https://www.capes.gov.br/images/stories/download/bolsas/Edital_001_PIBID_201 $1 \cdot \mathrm{pdf}$

Coordenação de Aperfeiçoamento de Pessoal de Nível Superior (CAPES). (2013) . Portaria n. 096, de 18 de julho de 2013. Regulamento do Programa Institucional de Bolsa de Iniciação à Docência - PIBID. Disponívelem : http://www.capes.gov.br/images/stories/download/legislacao/Portaria_096_18ju 113_AprovaRegulamentoPIBID.pdf

Conselho Nacional da Educação (CNE). (2001, 8 maio). Parecer CNE/CP 009/2001. Diretrizes Curriculares Nacionais para a Formação de Professores da Educação Básica, em nível superior, curso de licenciatura, de graduação plena. Brasília: CNE.

Cunha, M. I. (2004). A docência como ação complexa: o papel da didática na formação de professores. In: J. P. Romanowski, P. Martins \& S. Junqueira (Eds.), Conhecimento local e conhecimento universal: Pesquisa, didática e ação docente (pp. 34-42). Curitiba: Champagnat.

Franco, M. L. P. B. (2003). Análise de conteúdo. Brasília: Plano Editora.

Freire, P. (1974). Cartas a Cristina. São Paulo: Editora Paz e Terra.

Freire, P. (1992). Pedagogia da esperança. São Paulo: Editora Paz e Terra.

Garcia, M. C. (2010, ago.-dez.). o professor iniciante, a prática pedagógica e o sentido da experiência. Revista Brasileira de Pesquisa sobre Formação Docente, $02(03), 11-49$.

Gómez, A. P. (1997). O pensamento prático do professor: a formação do professor como profissional reflexivo. In: A. Nóvoa (Ed.), Os professores e a sua formação (pp. 93-114). Lisboa: Dom Quixote.

Martins Filho, A. J., Tristão, F. C. D., Rech, I. P. F. \& Schneider, M. L. (Eds.) . (2006). Infância plural: crianças do nosso tempo. Porto Alegre: Mediação.

$$
=55=
$$




\section{APOTHEKE}

EST Ú D I O D E

P I N T UR A

Nóvoa, A. (2008). Os professores e o "novo" espaço público da educação. In:

M. Tardif M. \& C. Lessard (Eds.), O ofício de professor: História, perspectivas e desafios internacionais (pp. 217-233). Petrópolis: Vozes.

Nóvoa, A. (2009). Professores: Imagens do futuro presente. Lisboa: Educa.

Tardif, M. (2002). Saberes docentes e formação profissional. Petrópolis: Vozes.

Tardif, M. \& Lessard, C. (2007). O trabalho docente: Elementos para uma teoria da docência como profissão de interações humanas (3. ed.). Rio de Janeiro: Vozes.

Tardif, M. \& Lessard, C. (2008). As transformações atuais do ensino: três cenários possíveis na evolução da profissão de professor? In: M. Tardif \& C.

Lessard, C. (Eds.), o ofício de professor: História, perspectivas e desafios internacionais (pp. 255-277). Petrópolis: Vozes.

Perrenoud, P. (2001). Ensinar: Agir na urgência, decidir na incerteza. Porto Alegre: Artmed Editora.

Souza, E. C. (2008). A vida com histórias de vida: apontamentos sobre a pesquisa na formação. In: E. Eggert, C. Traversini, E. Peres \& I. Bonin (Eds.), Trajetórias e processos de ensinar e aprender: Didática e formação de professores (Livro 1, pp. 135-154). Porto Alegre: EDIPUCRS.

Souza, E. C. (2014, jan.-abr.). Diálogos cruzados sobre pesquisa (auto) biográfica: análise compreensiva-interpretativa e política de sentido. Revista Educação, 39 (01), 39-50.

Zeicnher, K. M. (2008, maio-ago.). Uma análise crítica sobre a "reflexão" como conceito estruturante na formação docente. Educação e Sociedade, 29 (103), 535554 .

Alba Regina Battisti de Souza (UDESC)

Professora Associada do Departamento de Pedagogia. Universidade do Estado de Santa Catarina (UDESC), Brasil. Estágio Pós-doutoral em Educação na UNISINOS/RS.

gpddudescegmail.com

http://lattes.cnpq.br/3119208861422902

Lourival José Martins Filho (UDESC)

Professor Associado do Departamento de Pedagogia e do Programa de Pós-graduação em Educação. Universidade do Estado de Santa Catarina (UDESC), Brasil. Estágio Pós-doutoral em Educação e Religião na PUC/PR.

lourivalfaedegmail.com

http://lattes.cnpq.br/2491699071811572

$$
=56=
$$

